\title{
Descrições de sete novas espécies brasileiras de Amblycerus Thunberg (Coleoptera, Bruchidae) ${ }^{1}$
}

\author{
Cibele S. Ribeiro-Costa ${ }^{2}$
}

\begin{abstract}
Deseriptions of seven new Brazilian species of Amblycerus Thunberg (Coleoptera, Bruchidae). Seven new species here described and illustrated are: Amblycerus spiniger sp.n. from Pará, Amazonas, Rondônia and Espírito Santo; A. decoris sp.n. and A. manauara sp.n. from Amazonas; A. sclerolobii sp.n. from Amazonas and Minas Gerais; A. profaupar sp.n. from São Paulo, Paraná and Rio Grande do Sul; A. maculicollis sp.n. from Paraná and Rio Grande do Sul; A. pusillus sp.n. from Mato Grosso and Paraná.
\end{abstract}

KEY WORDS. Coleoptera, Bruchidae, Amblycerus, taxonomy

Em continuidade aos trabalhos descritivos de novas espécies de Amblycerus Thunberg, 1815 (KingSolver 1970, 1975, 1980, 1991; Ribeiro-CosTA \& KINGSOLVER 1993a,b; RIBEIRO-CosTA 1997, 1999a,b,c) são acrescentadas, nesta contribuição, mais sete espécies brasileiras ao gênero, totalizando cerca de 122 espécies com distribuição no Hemisfério Oeste.

A metodologia utilizada segue àquela descrita em RiBEIRO-CosTA (1997).

$\mathrm{O}$ material examinado pertence às seguintes instituições: (CMNH) Carnegie Museum of Natural History, Pittsburgh; (DZUP) Coleção de Entomologia Pe. Jesus S. Moure, Curitiba; (IFSA) Instituto Florestal de São Paulo, São Paulo; (MNRJ) Museu Nacional, Rio de Janeiro; (MZSP) Museu de Zoologia, Universidade de São Paulo, São Paulo; (USNM) National Museum of Natural History, Washington.

As espécies aqui descritas compartilham os seguintes caracteres: olhos grandes, grossamente facetados, protraídos lateralmente; lobo pós-ocular estreito. Antena serreada a partir do quarto artículo; último artículo subelíptico. Pronoto com sulco em parte do bordo posterior; carena lateral não-bifurcada anteriormente. Élitros com estrias fortemente impressas. Metepisterno sem área estriada. Metasterno lateralmente sem pontos grossos. Coxa posterior nos $2 / 3$ laterais com pontos grossos distribuídos mais centralmente; porção distal da margem ventral do fềmur posterior não-denteada.

\section{Amblycerus spiniger sp.n.}

Figs $1-10$

Dimensões. Comprimento $6,92-10,17 \mathrm{~mm}(\bar{x}=7,74 \mathrm{~mm} ; n=6)$; largura 4,25$6,17 \mathrm{~mm}(\overline{\mathrm{x}}=4,83 \mathrm{~mm} ; \mathrm{n}=6)$.

Tegumento. Coloração geral rufa. Algumas vezes testácea no dorso (excetuando-se o pigídio) e preta no restante do corpo.

1) Contribuição número 1141 do Departamento de Zoologia, Universidade Federal do Paraná.

2) Departamento de Zoologia, Universidade Federal do Paraná. Caixa Postal 19020, 81531-990 Curitiba, Paraná, Brasil.

E-mail: stra@bio.ufpr.br 
Pilosidade. Pronoto, escutelo e élitros com pilosidade flava a fulva; raramente linha de pêlos claros junto às bordas das interestrias. Restante do corpo com pilosidade flava a branca distribuída uniformemente; no pigídio os pêlos são levemente mais densos na metade basal e em linha mediano vertical.

Fronte levemente achatada. Índice ocular 2,8; sinus ocular 1/5 o diâmetro do olho; lobo pós-ocular 1/4,8 o maior comprimento do olho em vista lateral. Oitavo, nono e décimo artículos antenais com comprimento cerca de 1,5 vezes mais longos que largos (Fig. 1). Pronoto trapezoidal com margens laterais levemente arqueadas em vista dorsal; sem pontos grossos no disco; sulco cervical presente nos $1 / 3$ laterais; carena lateral aproximadamente a metade ou muito além da metade do comprimento do pronoto lateralmente. Processo prosternal largo, moderadamente expandido além das coxas anteriores. Escutelo cerca de 1,3 vezes mais longo que largo, com ápice bi, tri ou quadridenteado (Figs 2-4). Élitros em corte transversal convexos ao longo da sutura, subtruncados apicalmente. Metepisterno sem pontos grossos; eixo transversal do sulco metepisternal divergindo dorsalmente, eixo longitudinal aproximadamente a metade ou além da metade do comprimento do metepisterno. Coxas anteriores aparentemente no mesmo nível que as médias em vista lateral. Fêmur posterior (Fig. 5) cerca de 2,9 vezes mais longo que largo. Tíbia posterior (Fig. 5) com um longo espinho coronal externo; esporão lateral 2,6 vezes o comprimento do mediano, o primeiro artículo tarsal posterior 1,2 vezes tão longo quanto o esporão lateral e cerca de 3,0 vezes o comprimento do mediano; face ventral convexa com linha de pontos e cerdas grossas inconspícuas nas margens. Pigídio do macho e da fêmea em forte declive em vista lateral; o do macho arredondado ou subtruncado apicalmente (Fig. 6) e o da fêmea suavemente emarginado (Fig. 7). Entre o quarto e quinto urosternitos visíveis do macho pequena área pontiaguda mediana (Fig. 6); margem do quinto esterno suavemente emarginado no macho (Fig. 6) e subtruncado na fêmea (Fig. 7).

Terminália do macho (Figs 9, 10). Oitavo tergito emarginado apicalmente (Fig. 8). Lobo médio (Fig. 10) com comprimento 3,3 vezes a sua maior largura; valva ventral curta com margens laterais levemente côncavas, ápice arredondado; valva dorsal subovalada. Região basal do saco interno com um par de escleritos anteriores (Fig. 10-EAN) subovalado e com um pequeno dente subasal. Região mediana do saco interno com um par de escleritos laminares medianos levemente arqueados e serreados no quarto basal de sua margem, os dentes aproximados; dois pares de escleritos laterais, um sub-retangular com dois ou três dentes (Fig. 10-EL1) ou com dentes separados formando dois escleritos com um dente cada, outro par (Fig. 10-EL2) com dois dentes cada um na região subasal; dois escleritos ímpares, um (Fig. 10-EI1) em forma de foice invertida e outro (Fig. 10-EI2) menor, cerca de 0,3 vezes tão longo quanto os laminares, com hastes apicais levemente separadas e com dentes na margem apical, arredondada. Na região apical do saco interno um esclerito com hastes longas gradualmente convergentes (Fig. 10-EA). Região basal e mediana do saco interno com alguns espinhos, dentículos presentes na região mediana, estes simples ou micro-serreados. Tégmen (Fig. 9) com suave emarginação arredondada entre os delgados lobos laterais.

Discussão taxonômica. Esta espécie compartilha vários caracteres externos com Amblycerus pollens (Sharp, 1885). Internamente, com relação a terminália do macho, observa-se que os escleritos do saco interno são muito diferentes e contri- 
buem para a separação das mesmas. Amblycerus spiniger diferencia-se externamente tanto de $A$. pollens quanto de outras espécies brasileiras do gênero pela presença de um longo espinho coronal externo, na tíbia posterior (Fig. 5) além do grande número de escleritos do saco interno do macho (Fig. 10).

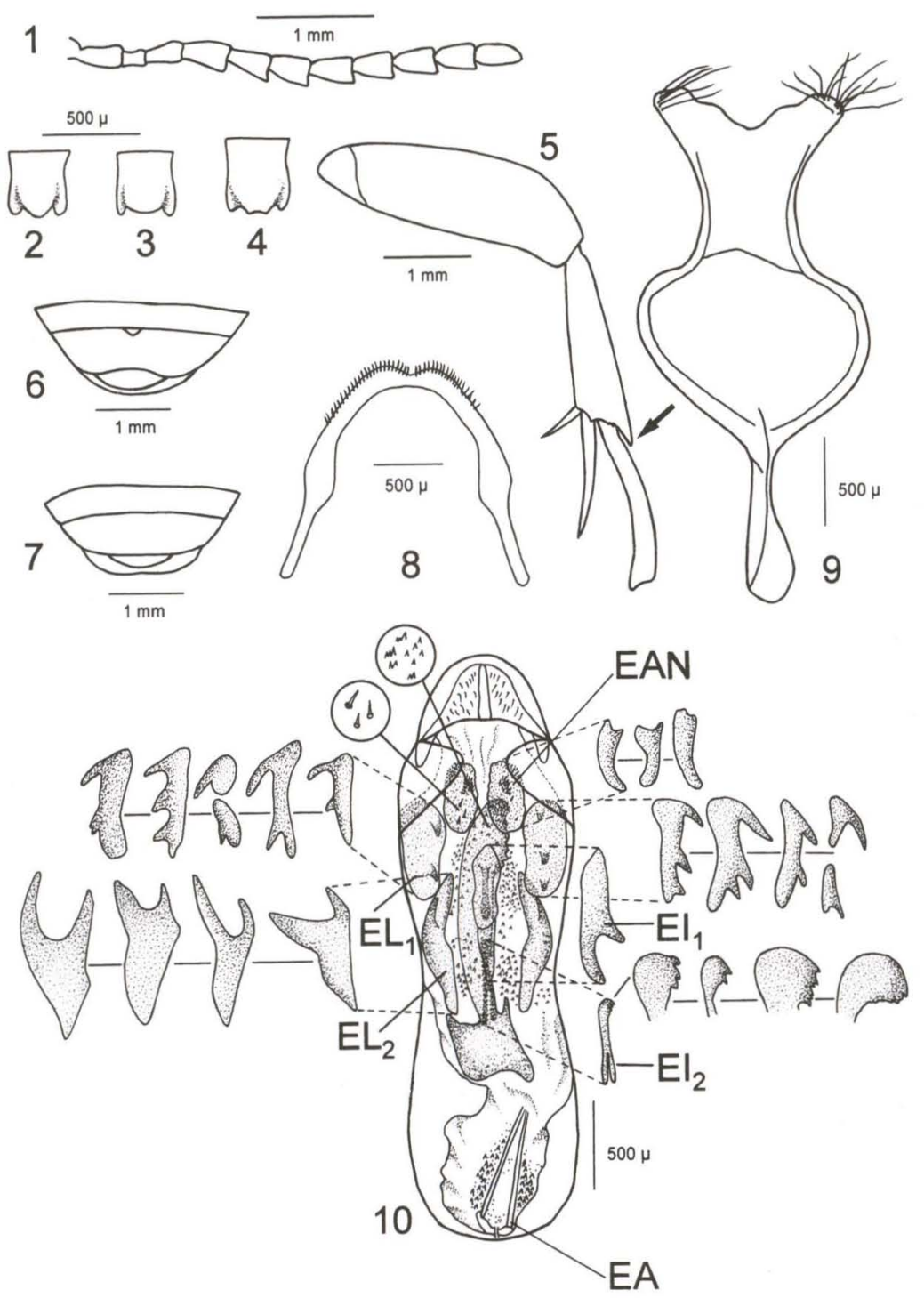

Figs 1-10. Amblycerus spinigersp.n.. (1) Antena; (2-4) escutelo; (5) perna posterior; (6) últimos urosternitos do macho; (7) últimos urosternitos da fêmea; (8-10) terminália do macho: (8) oitavo tergito, (9) tégmen, (10) lobo médio. (EAN) Esclerito anterior, $\left(E I_{1,2}\right)$ esclerito impar, $\left(E L_{1,2}\right)$ escleritos laterais; (EA) esclerito apical. 
Holótipo macho. Brasil, Rondônia: Ouro Preto d'Oeste, 29.X.1987, C. Elias leg., Projeto Polonoroeste, (DZUP). Sete parátipos do Brasil - um com os mesmos dados do holótipo, (DZUP); um Amazonas: Moura, Rio Negro, VIII a XI-1943, A. Parko leg., (MNRJ); dois [Pará], Santarém, [H. H. Smith leg.], Acc. No2966, (CMNH); um [Pará], Taquara, XI, [H. H. Smith leg.], Acc.No.2966, (USNM); um [Pará], Taperina [Taperinha], [H. H. Smith leg.], Acc.No. 2966, (CMNH) e um Espirito Santo, Linhares, IX.1978, M. Alvarenga leg., (CMNH).

Etimologia. O nome da espécie refere-se a presença de um longo espinho coronal externo na tíbia posterior.

\section{Amblycerus decoris sp. $\mathbf{n}$.}

Figs 11-19

Dimensões. Comprimento 3,17mm; largura 5,00mm.

Tegumento. Coloração geral do corpo, testácea. Os três primeiros artículos antenais testáceo-pálidos e cabeça, região mediano-ventral do tórax e pernas, testáceo-escuros.

Pilosidade. Cabeça, apêndices e região mediano-ventral do tórax com pilosidade flava a branca distribuída uniformemente; maior parte do metepisterno fulvo. Pronoto (figs 12 e 13) flavo com grande mancha irregular fulva nas laterais; alguns pêlos marrons dispersos. Escutelo (Fig. 12) flavo a branco. Élitros (Fig. 12) fulvos com pilosidade flava a branca em linha junto às bordas das interestrias e formando um grumo em cada élitro na metade posterior da quinta interestria. Pigídio (Figs 12 e 15) marrom nas áreas ântero-laterais e em pequena mancha arredondada central; restante da superfície com pêlos flavos a brancos adensados e fulvos. Abdome com pêlos flavos, fulvos e alguns marrons; os flavos suavemente mais adensados em área arredondada lateral do primeiro e segundo urosternitos visíveis.

Fronte levemente achatada. Índice ocular 3,6; sinus ocular 1/3,6 o diâmetro do olho; lobo pós-ocular 1/16,7 o maior comprimento do olho em vista lateral. Oitavo, nono e décimo artículos antenais com comprimento cerca de 1,1 vezes mais longo que largo (Fig. 11). Pronoto trapezoidal com margens laterais levemente arqueadas em vista dorsal; pontos grossos do disco menores que os pontos grossos das laterais; sulco cervical presente nos terços laterais; carena lateral longa, muito além da metade do comprimento do pronoto lateralmente. Processo prosternal largo, moderadamente expandido além das coxas anteriores. Escutelo cerca de 1,4 vezes mais longo que largo, com ápice tridenteado; os dentes de igual tamanho (Fig. 14). Élitros, em corte transversal, convexos ao longo da sutura, subtruncados apicalmente. Metepisterno sem pontos grossos; eixo transversal do sulco metepisternal divergindo dorsalmente, eixo longitudinal aproximadamente a metade do comprimento do metepisterno. Coxas anteriores aparentemente no mesmo nível que as médias em vista lateral. Fêmur posterior (Fig. 16) cerca de 2,5 vezes tão longo quanto largo. Tíbia posterior (Fig. 16) com espinhos coronais aproximadamente de igual tamanho; esporão lateral cerca de 2,4 vezes o comprimento do mediano e cerca de 1,3 vezes tão longo quanto o comprimento do primeiro artículo tarsal posterior; esporão mediano cerca de três vezes o comprimento do primeiro artículo tarsal posterior; face ventral plańa com linha de pontos e cerdas grossas conspícuas nas margens. 

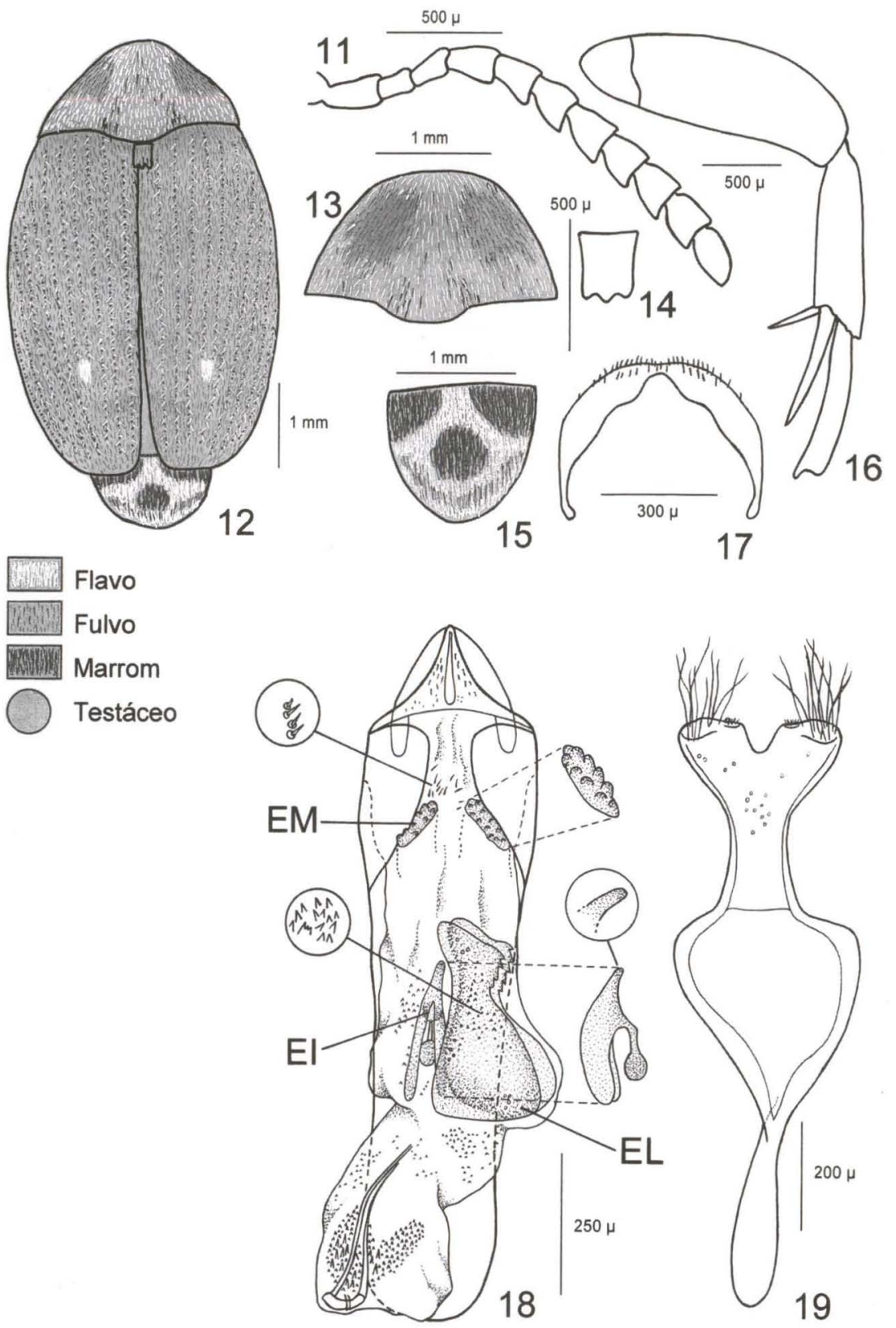

Figs 11-19. Amblycerus decoris sp.n.. (11) Antena; (12) padrão de coloração do tegumento (círculo) e pilosidade (retângulo) no dorso; (13) pronoto; (14) escutelo; (15) pigídio; (16) perna posterior; (17-19) terminália do macho: (17) oitavo tergito, (18) lobo médio, (19) tégmen. (EM) Esclerito médio, (EI) esclerito impar, (EL) esclerito laminar. 
Pigídio do macho em forte declive; arredondado apicalmente. Quinto esterno abdominal visível suavemente emarginado no macho.

Terminália do macho (Figs 17-19). Oitavo tergito arredondado apicalmente (Fig. 17). Lobo médio (Fig. 18) com comprimento 4,2 vezes a sua maior largura na região basal; valva ventral moderadamente longa, com margens laterais côncavas e ápice afilado; valva dorsal subtriảngular, margens laterais levemente convexas, ápice arredondado. Região basal do saco interno sem escleritos anteriores e posteriores; um par de escleritos médios pequenos, alongados e com protuberâncias arredondadas (Fig. 18-EM). Região mediana do saco interno com um par de escleritos laminares (Fig. 18-EL), moderadamente sinuosos e serreados na margem subasal; os dentes aproximados; um esclerito ímpar (Fig. 18-EI) em forma de forquilha, cerca de 0,7 vezes tão longo quanto os laminares com três hastes, a mediana mais curta termina em circunferência. Na região apical do saco interno um esclerito de hastes muito longas gradualmente convergentes. Região basal do saco interno com vários espinhos curtos, dentículos simples ou micro-serreados presentes na região mediana. Tégmen (Fig. 19) com emarginação arredondada entre os alargados lobos laterais.

Discussão taxonômica. Esta espécie diferencia-se das outras espécies brasileiras do gênero, principalmente pelo padrão de coloração de pilosidade no dorso e forma dos escleritos do saco interno do macho.

Holótipo macho, BRASIL, Amazonas: Manaus, 02³0'S-060¹5'W, (Hwy ZF Z, Km 19.5, ca 60Km N.), 18.VIII.79, Adis, Erwin, Montgomery, et al. leg., Canopy Fogging Project TRS\#10, (USNM).

Etimologia. O nome da espécie refere-se a ornamentação do pigídio.

\section{Amblycerus sclerolobii sp.n.}

Figs 20-25

Dimensões. Comprimento $5,83-7,58 \mathrm{~mm}(\overline{\mathrm{x}}=6,92 \mathrm{~mm} ; \mathrm{n}=9)$; largura 3,50 $4,33 \mathrm{~mm}(\overline{\mathrm{x}}=4,08 \mathrm{~mm} ; \mathrm{n}=9)$.

Tegumento. Coloração geral, rufa. Antenas, esternos torácicos e pernas geralmente testáceos.

Pilosidade. Corpo com pilosidade flava distribuida uniformemente; no pigídio algumas vezes suave adensamento de pêlos em linha vertical mediana. Região ventral do tórax e apêndices frequentemente com pêlos mais claros.

Fronte convexa. Índice ocular 3,9; sinus ocular 1/3,7 o diâmetro do olho; lobo pós-ocular $1 / 25$ o maior comprimento do olho em vista lateral. Oitavo, nono e décimo artículos antenais com comprimento cerca de 1,3 vezes mais longos que largos (Fig. 20). Pronoto semicircular com margens laterais moderadamente arqueadas em vista dorsal; sem pontos grossos no disco; sulco cervical presente nos $1 / 3$ laterais; carena lateral curta, até aproximadamente a metade do comprimento do pronoto lateralmente. Processo prosternal delgado, não expandido além das coxas anteriores. Escutelo 1,2 vezes mais longo que largo, com ápice tridenteado; os dentes com igual tamanho (Fig. 21). Élitros, em corte transversal, planos ao longo da sutura, subtruncados apicalmente. Metepisterno com pontos grossos esparsos ou ausentes; eixo transversal do sulco metepisternal divergindo dorsalmente, eixo longitudinal menor que a metade ou aproximadamente a metade do comprimento do metepister-

Revta bras. Zool. 17 (2): 323 - 338, 2000 


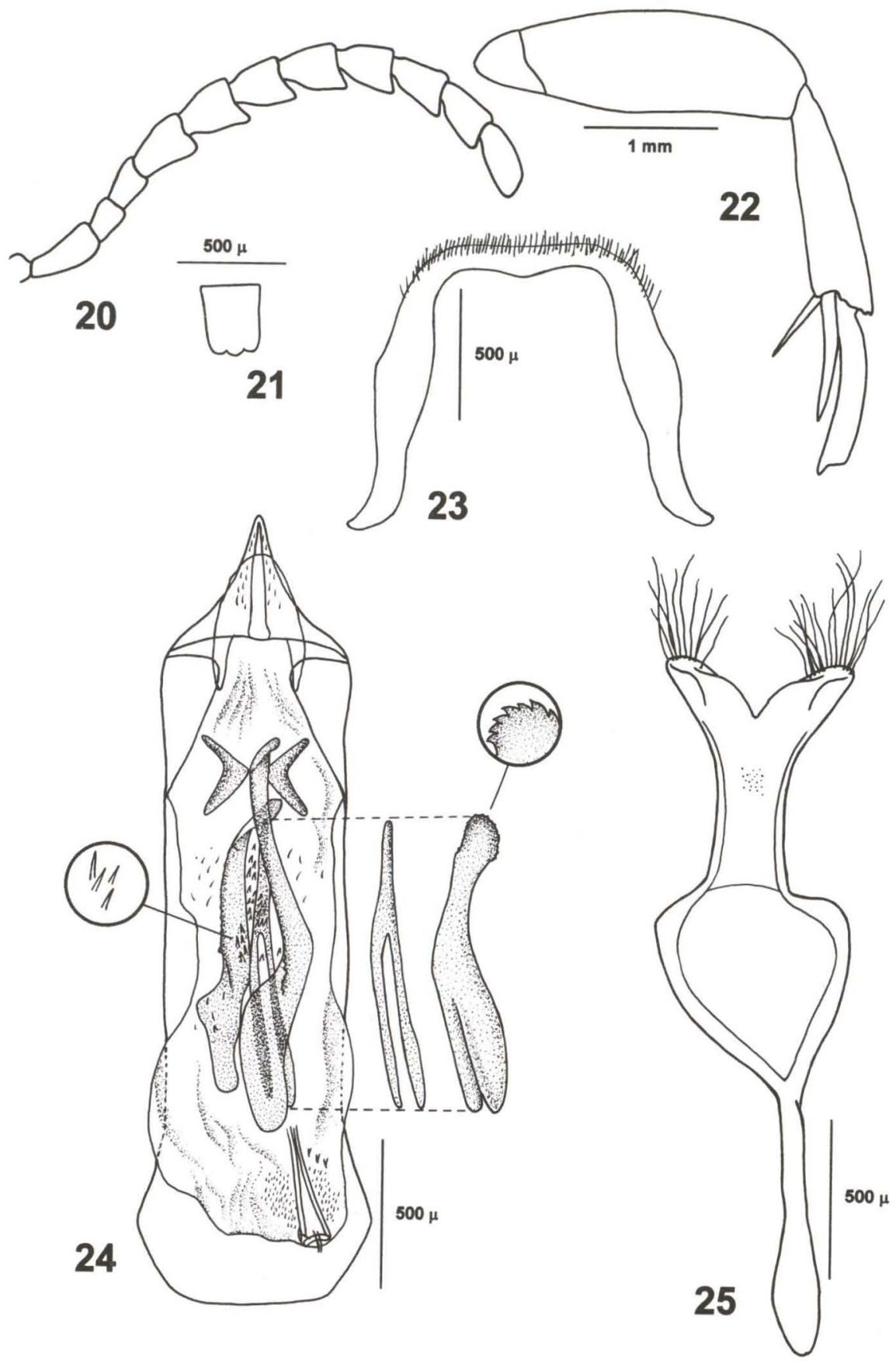

Figs 20-25. Amblycerus sclerolobii sp.n.. (20) Antena; (21) escutelo; (22) perna posterior; (23-25) terminália do macho: (23) oitavo tergito do macho; (24) lobo médio; (25) tégmen. 
no. Coxas anteriores nitidamente em nível mais abaixo que as médias em vista lateral. Fêmur posterior (Fig. 22) cerca de 2,8 vezes tão longo quanto largo. Tíbia posterior (Fig. 22) com espinhos coronais aproximadamente de igual tamanho; esporão lateral cerca de 1,8 vezes o comprimento do mediano, o primeiro artículo tarsal posterior cerca de 1,1 vezes tão longo quanto o lateral e cerca de 2,3 vezes o esporão mediano; face ventral convexa com linha de pontos e cerdas grossas inconspícuas nas margens. Pigídio do macho em forte declive e da fềmea em declive moderado em vista lateral; subtruncado apicalmente. Quinto esterno abdominal visível suavemente emarginado no macho e arredondado na fêmea.

Terminália do macho (Figs 23-25). Oitavo tergito truncado apicalmente (Fig. 23). Lobo médio (Fig. 24) com comprimento 4,4 vezes a sua maior largura na região basal; valva ventral moderadamente longa, com margens laterais côncavas e ápice afilado; valva dorsal subovalada. Região basal do saco interno sem escleritos anteriores e médios; um par de escleritos posteriores em forma de dente fortemente encurvado. Região mediana do saco interno com um par de escleritos laminares de tamanhos conspicuamente diferentes, moderadamente sinuosos e serreados na margem até a região mediana; os dentes aproximados; um esclerito ímpar em forma de forquilha, com igual tamanho do esclerito laminar mais curto, base arredondada com margem serreada e hastes apicais levemente separadas. Na região apical do saco interno um esclerito com hastes longas, gradualmente convergentes. Região basal e mediana do saco interno com vários espinhos curtos, dentículos adensados presentes na região mediana. Tégmen (Fig. 25) com emarginação aguda entre os delgados lobos laterais.

Discussão taxonômica. Amblycerus sclerolobii mostra-se mais afim de $A$. manauara, A. kingsolveri Ribeiro-Costa, 1993 e A. marinonii Ribeiro-Costa, 1993. Alguns caracteres externos que evidenciam este relacionamento são: coloração da pilosidade no corpo, formato da cabeça, comprimento da carena lateral do pronoto e élitros planos em corte transversal. Amblycerus sclerolobii distingue-se externamente pela coloração do tegumento na região ventral do tórax, algumas vezes mais escurecido e internamente, pelo tamanho do esclerito ímpar em forma de forquilha, situado na região mediana do saco interno do macho.

Holótipo macho, BRASIL, Minas Gerais: Viçosa, 19-XI-986, G.P. Santos leg., em semente de mamoneira-branca, Sclerolobium sp., (DZUP). Onze parátipos do Brasil: oito com os mesmos dados do holótipo, 2 (DZUP), 2 (MZSP), 2 (MNRJ), 2 (USNM); um Amazonas, Rio Javari, Estirão do Ecuador, X.1979, M. Alvarenga leg., (CMNH) e dois apenas com as informações 5.X.1936, (EQ 045238), Sclerolobium denudatum, (USNM).

Etimologia. O nome da espécie refere-se a planta hospedeira do holótipo.

\section{Amblycerus manauara sp.n.}

Figs 26-28

A descrição de A. manauara sp.n. é semelhante à de A. sclerolobii sp.n. exceto pelos seguintes caracteres.

Dimensões. Comprimento $6,83 \mathrm{~mm}$; largura $4,17 \mathrm{~mm}$.

Pilosidade. Pêlos não adensados no pigídio.

Revta bras. Zool. 17 (2): 323 - 338, 2000 
Índice ocular 4,8; sinus ocular 1/3,3 o diâmetro do olho; lobo pós-ocular 1/30,0 o maior comprimento do olho em vista lateral. Escutelo cerca de 1,3 vezes mais longo que largo. Metepisterno sem pontos grossos. Fêmur posterior cerca de 2,8 vezes tão longo quanto largo. Tíbia posterior (Fig. 26) com esporão lateral cerca de 1,6 vezes o comprimento do mediano; o primeiro artículo tarsal posterior cerca de 1,1 vezes tão longo quanto o lateral e com o dobro do esporão mediano. Pigídio do macho em forte declive em vista lateral, suavemente emarginado apicalmente. Quinto esterno abdominal visível levemente emarginado no macho. Fêmea não conhecida.

Terminália do macho (Figs 27, 28). Oitavo tergito emarginado apicalmente. Lobo médio (Fig. 27) com comprimento 4,4 vezes a sua maior largura na região basal; valva ventral longa com margens laterais levemente sinuosas e ápice ligeiramente agudo; valva dorsal semicircular com margens laterais fortemente convexas. Região basal do saco interno sem escleritos anteriores e posteriores; dois pares de escleritos médios, um par em forma de dente e o outro delgado com base levemente alargado e serreado na margem. Região mediana do saco interno com um par de escleritos laminares longos com dois dentes agudos na margem; os dentes muito afastados; um esclerito em forma de forquilha, cerca de 0,9 vezes tão longo quanto os laminares, com hastes apicais moderadamente separadas e base serreada na margem. Região basal e mediana do saco interno sem espinhos. Tégmen (Fig. 28) com emarginação aguda entre os delgados lobos laterais.

Discussão taxonômica. $\mathrm{O}$ aspecto externo lembra $A$. kingsolveri, A. marinonii e A. sclerolobii, mas a terminália do macho evidencia a diferenciação das mesmas.

Holótipo macho, BRASIL, Amazonas: Uypizanga [Uypiranga], Rio Negro, (14 Km de Manaus, Alt. 300 pés), XII.1941, A. Rabaut leg., (USNM).

Etimologia. O nome da espécie refere-se a localidade do holótipo.

\section{Amblycerus profaupar sp.n.}

\section{Figs 29-36}

Dimensões. Comprimento 2,50-3,50mm ( $\bar{x}=3,08 \mathrm{~mm}$; $n=10)$; largura 1,50$2,08(\bar{x}=5,08 \mathrm{~mm} ; \mathrm{n}=10)$.

Tegumento. Coloração geral testácea, raramente rufa.

Pilosidade. Cabeça, apêndices (exceto coxa posterior), região mediano-ventral do tórax e abdome com pilosidade flava distribuída uniformemente, estes algumas vezes adensados em áreas arredondadas laterais, nos urosternitos visíveis. Restante do corpo, exceto pigídio, com pilosidade flava a branca entremeada com pilosidade fulva ou marrom formando um padrão suavemente manchado (Fig. 29). Escutelo flavo. Pigídio flavo com mancha alongada central marrom (Fig. 29).

Fronte levemente achatada. Índice ocular 3,5; sinus ocular 1/7,1 o diâmetro do olho; lobo pós-ocular 1/14,3 o maior comprimento do olho em vista lateral. Oitavo, nono e décimo artículos antenais com comprimento cerca de 0,8 vezes a largura; último artículo subelíptico ou subgloboso (Fig. 30). Pronoto semicircular com margens laterais moderadamente arqueadas em vista dorsal; pontos grossos no disco de tamanho menor que os grossos das laterais ou ausentes; sulco cervical ausente; carena lateral longa, muito além da metade do comprimento do pronoto 


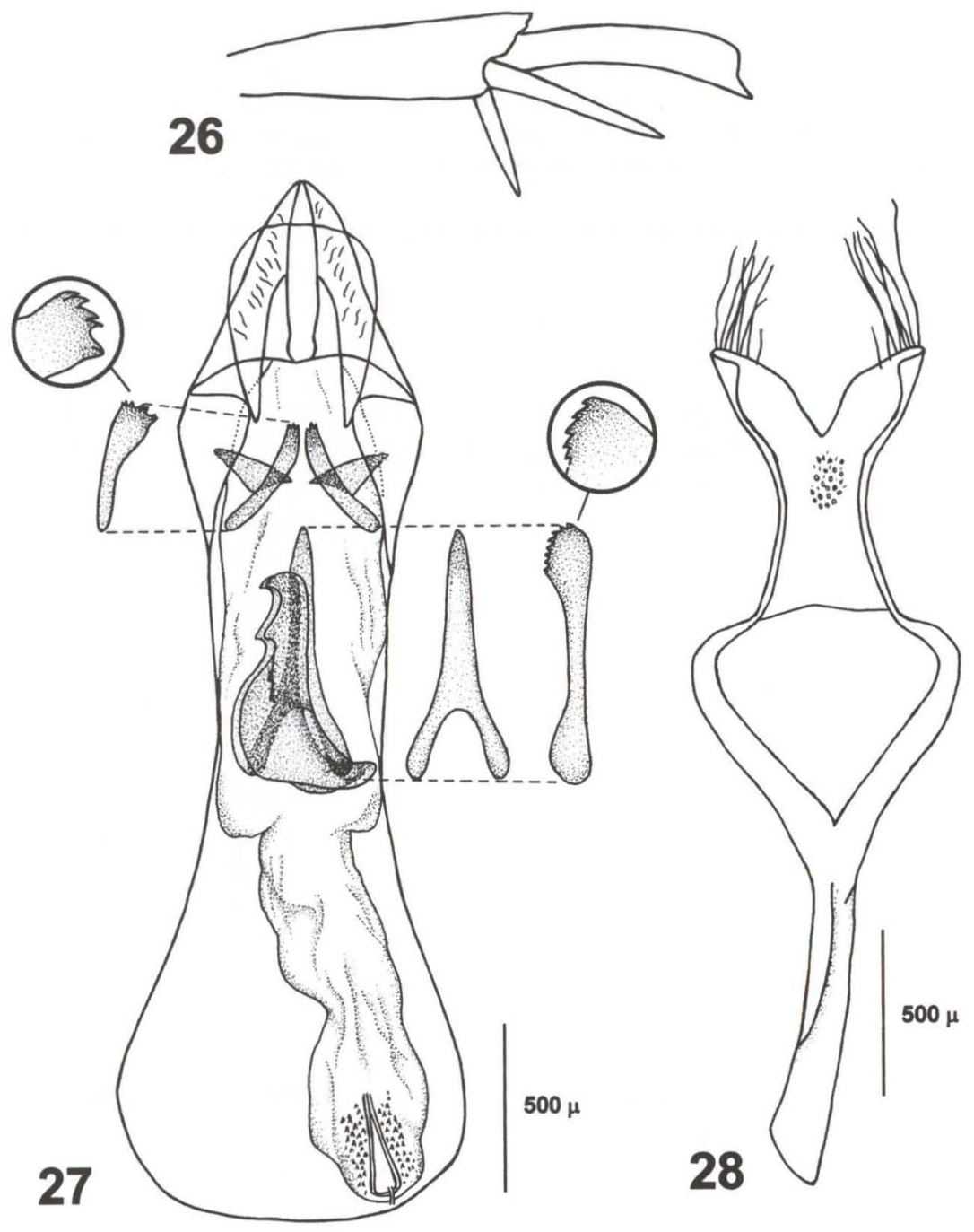

Figs 26-28. Amblycerus manauara sp.n.. (26) Ttibia e primeiro artículo tarsal da perna posterior; (27-28) terminália do macho: (27) lobo médio; (28) tégmen.

lateralmente. Processo prosternal delgado, levemente expandido além das coxas anteriores. Escutelo cerca de 2,0 ou 2,2 vezes mais longo que largo, com ápice bidenteado, arredondado ou truncado (Figs 31-33). Élitros em corte transversal convexos ao longo da sutura, arredondados ou subtruncados apicalmente. Metepisterno com alguns pontos grossos; eixo transversal do sulco metepisternal reto ou divergindo dorsalmente, eixo longitudinal além da metade do comprimento do metepisterno. Coxas anteriores aparentemente mais acima que as médias em vista lateral. Fêmur posterior (Fig. 34) cerca de 2,5 vezes tão longo quanto largo. Tíbia posterior com espinhos 

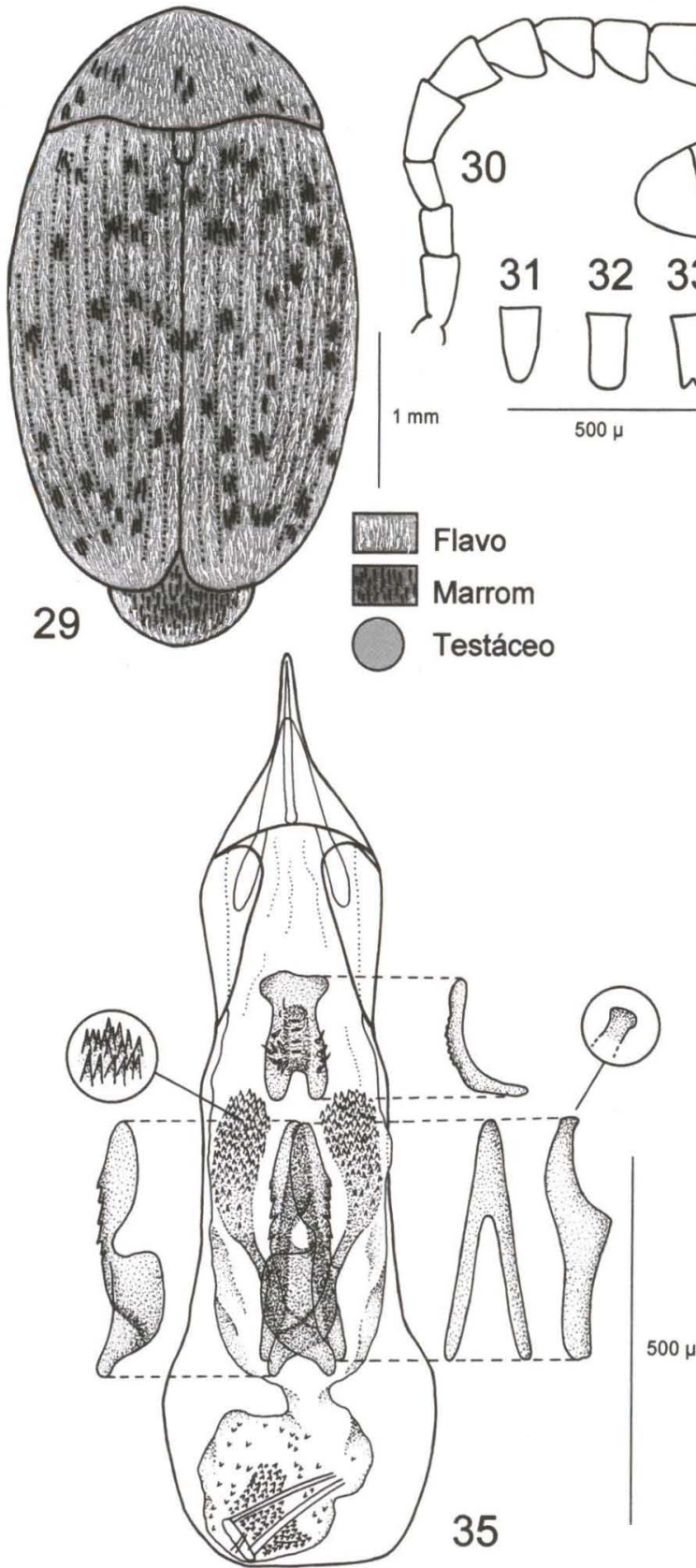
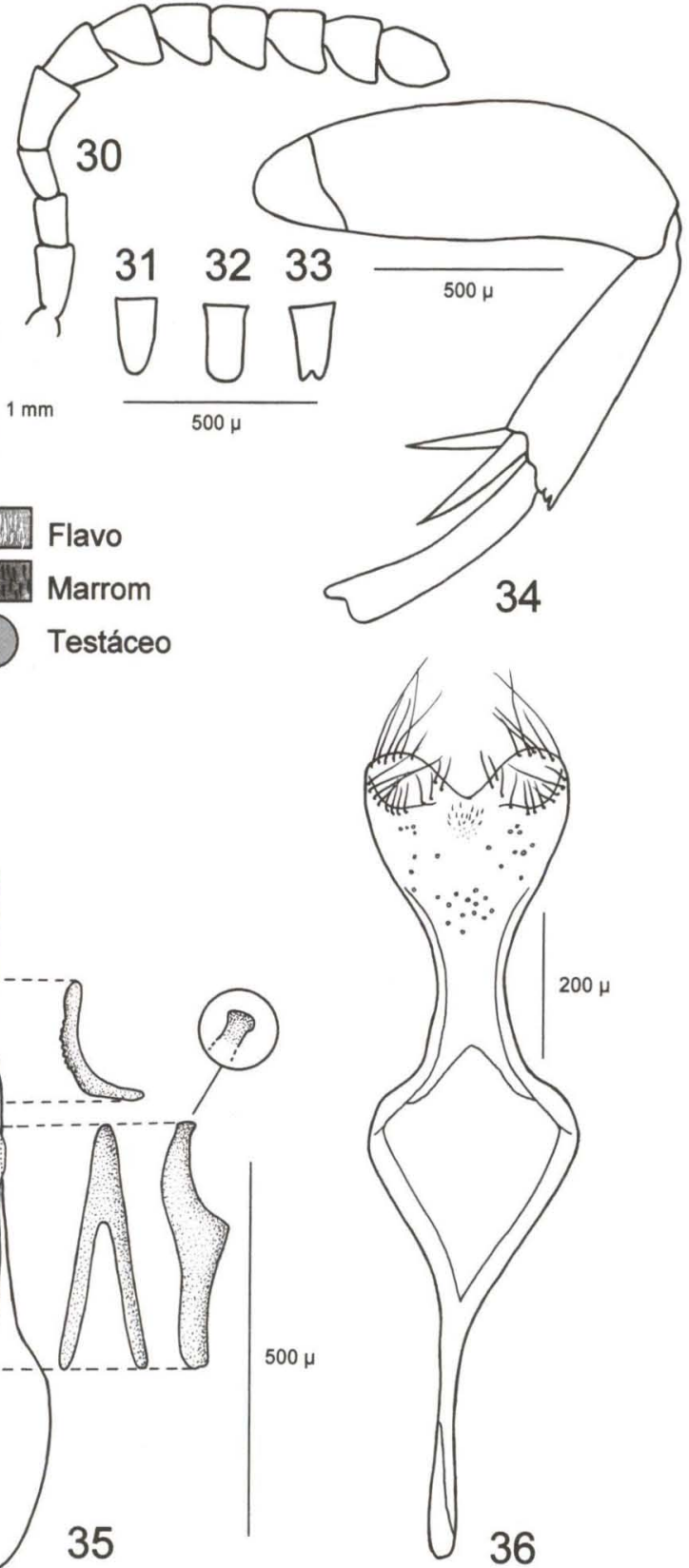

Figs 29-36. Amblycerus profaupar sp.n.. (29) Padrão de coloração do tegumento (círculo) e pilosidade (retângulo) no dorso; (30) antena; (31-33) escutelo; (34) perna posterior; (35-36) terminália do macho: (35) lobo médio; (36) tégmen. 
coronais aproximadamente de igual tamanho; esporão lateral cerca de 1,4 vezes o comprimento do mediano; o primeiro artículo tarsal posterior cerca de 1,6 vezes tão longo quanto o lateral e cerca de 2,1 vezes o esporão mediano; face ventral convexa com linha de pontos e cerdas grossas inconspícuas nas margens. Pigídio do macho e da fêmea em forte declive em vista lateral; arredondado apicalmente. Quinto esterno abdominal visível levemente truncado no macho e arredondado na fềmea.

Terminália do macho (Figs 35-36). Oitavo tergito arredondado apicalmente. Lobo médio (Fig. 35) com comprimento 4,9 vezes a sua maior largura na região basal; valva ventral longa, com margens laterais côncavas e ápice afilado; valva dorsal subtriangular, margens laterais retas, ápice levemente acuminado. Região basal do saco interno sem escleritos anteriores e médios; um esclerito posterior côncavo finamente serreado na margem mediana, com duas hastes apicais curtas e base truncada. Região mediana do saco interno com um par de escleritos laminares, moderadamente sinuosos, serreados na margem submediana; os dentes aproximados; um esclerito ímpar em forma de forquilha, cerca de 0,9 vezes tão longo quanto os laminares, com hastes apicais moderadamente separadas e base arredondada; um par de escleritos situados aos lados dos laminares, alongados, levemente sinuosos, com muitos dentículos adensados na metade basal e haste apical bem definida. $\mathrm{Na}$ região apical do saco interno um esclerito com hastes longas, gradualmente convergentes. Região basal e mediana do saco interno com vários espinhos curtos. Tégmen (Fig. 36) com emarginação arredondada entre os lobos laterais, estes também arredondados.

Discussão taxonômica. ROMERo et al. (1996) estabeleceram grupos de espécies de Amblycerus provenientes dos Estados Unidos e México. Um desses grupos, denominado "scutellaris" compõe-se por 8 espécies, das quais 7 são citadas como ocorrentes em sementes de espécies de Cordia L. (Boraginaceae). Amblycerus profaupar sp.n. e A. maculicollis sp.n., além de ocorrerem em planta-hospedeira do mesmo gênero, mostram-se intimamente afins e compartilham vários caracteres com este agrupamento de espécies.

Amblycerus profaupar sp.n. é parcialmente simpátrica com A. maculicollis sp.n. porém distingue-se desta pela ausência de áreas de tegumento escurecido no pronoto e escutelo (Fig. 29) e, pelo tamanho do lobo médio e formato do esclerito da região basal, do saco interno do macho (Fig. 35).

Holótipo macho, Brasil, Paraná: Ponta Grossa (V. Velha, Reserva Iapar, BR376), 06.X.1986, Lev. Ent. Profaupar, Malaise, (DZUP). 48 parátipos do Brasil: 19 São Paulo, Est. Exp. Bauru, Instituto Florestal, (Lat. 22 ${ }^{\circ} 19^{\prime}$ S, Long. $49^{\circ} 04^{\prime} \mathrm{W}$, 2.10.84), E.P. Teixeira leg., em louro-pardo, Cordia trichotoma, 1 (MZSP), 4 (MNRJ), 5 (IFSA), 9 (DZUP); um São Paulo, Itu, (Faz. Pau d'Alho), 29.X.1965, U. Martins leg., (MZSP); um com os mesmos dados 27.IX.1959, (MZSP) e 27 Rio Grande do Sul, Santa Maria, 6-VIII-1971, D. Link leg., em sementes de Cordia hypoleuca, 1 (MZSP), 1 (MNRJ), 1(IFSA), 9 (DZUP), 15 (USNM).

Etimologia. O nome da espécie refere-se ao projeto intitulado Levantamento da Fauna Entomológica do Estado do Paraná (PROFAUPAR). 


\section{Amblycerus maculicollis sp.n.}

Figs $37-39$

Amblycerus maculicollis sp.n. é semelhante a A. profaupar sp.n. exceto pelos seguintes caracteres:

Dimensões. Comprimento 2,83-4,50mm $(\overline{\mathrm{x}}=3,33 \mathrm{~mm} ; \mathrm{n}=10)$; largura 1,67$2,92 \mathrm{~mm}(\overline{\mathrm{x}}=2,00 \mathrm{~mm} ; \mathrm{n}=10)$.

Tegumento. Coloração geral, testácea. No terço mediano do pronoto e área dos élitros em torno do escutelo, testáceo muito escuro a preto (Fig. 37). Esternos torácicos e coxas posteriores com áreas escurecidas.

Pilosidade. Marrom predominante nas áreas de tegumento escuro do pronoto e élitros (Fig. 37).

Índice ocular 3,0; sinus ocular $1 / 3,7$ o diâmetro do olho. Oitavo, nono e décimo artículos antenais tão longos quanto largos, último artículo subelíptico ou subgloboso. Processo prosternal algumas vezes não expandido além das coxas anteriores. Eixo transversal do sulco metepisternal na maioria das vezes levemente divergindo dorsalmente, raramente reto. Fêmur posterior cerca de 2,6 vezes tão longo quanto largo. Tíbia posterior com esporão lateral cerca de 1,7 vezes tão longo quanto o comprimento do primeiro artículo tarsal posterior. Quinto esternito suavemente emarginado no macho e arredondado na fêmea.

Terminália do macho (Figs 38-39). Lobo médio (Fig. 38) com comprimento 5,6 vezes a sua maior largura na região basal; valva dorsal com margens laterais levemente côncavas e ápice arredondado. Região basal do saco interno com um esclerito posterior subtriangular, arredondado apicalmente. Região mediana do saco interno com um esclerito ímpar em forma de forquilha cerca de 1,2 vezes tão longo quanto os laminares. Tégmen (Fig. 39) com fraca emarginação entre os arredondados lobos laterais.

Discussão taxonômica em A. profaupar sp.n.

Holótipo macho, BrasiL, Rio Grande do Sul: Santa Maria, 6.VIII-1971, D. Link leg., em sementes de Cordia hypoleuca, (DZUP). Seis parátipos do Brasil: quatro com os mesmos dados do holótipo, 1 (DZUP), 3 (USNM); um Paraná: Guarapuava, (Est. Águas Sta.Clara), 01.XI.1986, Lev. Ent. Profaupar, lâmpada, (DZUP) e um Pinhão, 26-III-92, R. Misiuta leg. (DZUP).

Etimologia. O nome da espécie refere-se a presença de área escurecida no pronoto e em torno do escutelo (Fig. 37).

\section{Amblycerus pusillus sp.n.}

Figs $40-43$

A descrição de $A$. pusillus sp.n. é semelhante a $A$. profaupar sp.n. exceto pelos seguintes caracteres.

Dimensões: comprimento $2,75-3,75 \mathrm{~mm}(\overline{\mathrm{x}}=3,17 \mathrm{~mm} ; \mathrm{n}=5)$; largura 1,58 $2,08 \mathrm{~mm}(\overline{\mathrm{x}}=1,83 \mathrm{~mm} ; \mathrm{n}=5)$.

Índice ocular 4,3; sinus ocular $1 / 4,6$ o diâmetro do olho; lobo pós-ocular $1 / 20$ o maior comprimento do olho em vista lateral. Oitavo, nono e décimo artículos antenais com comprimento cerca de 1,1 vezes mais longos que largos. Pronoto sem 

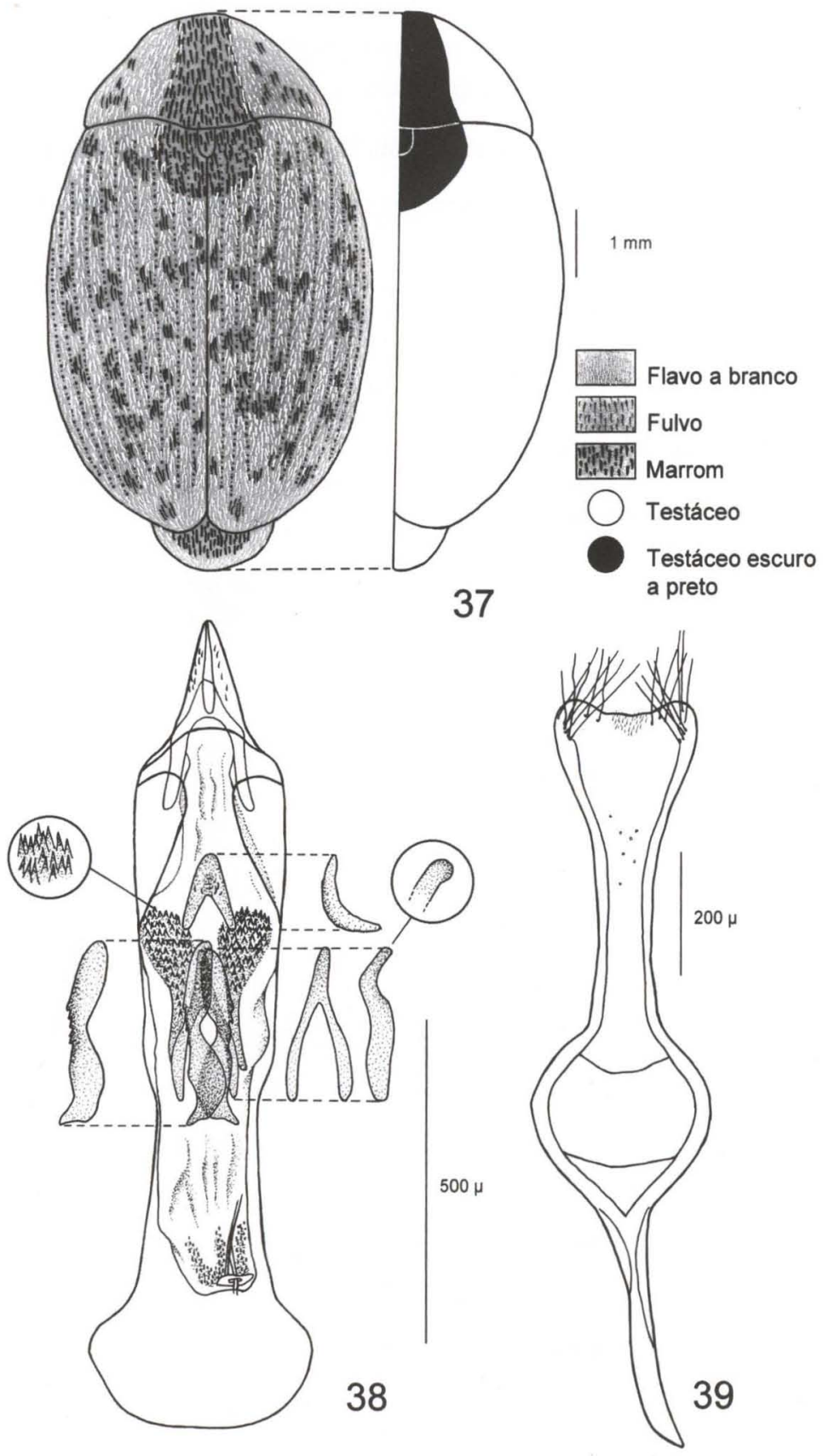

Figs 37-39. Amblycerus maculicollis sp.n.. (37) Padrão de coloração do tegumento (circulo) e pilosidade (retângulo) no dorso; (38-39) terminália do macho: (38) lobo médio; (39) tégmen. 

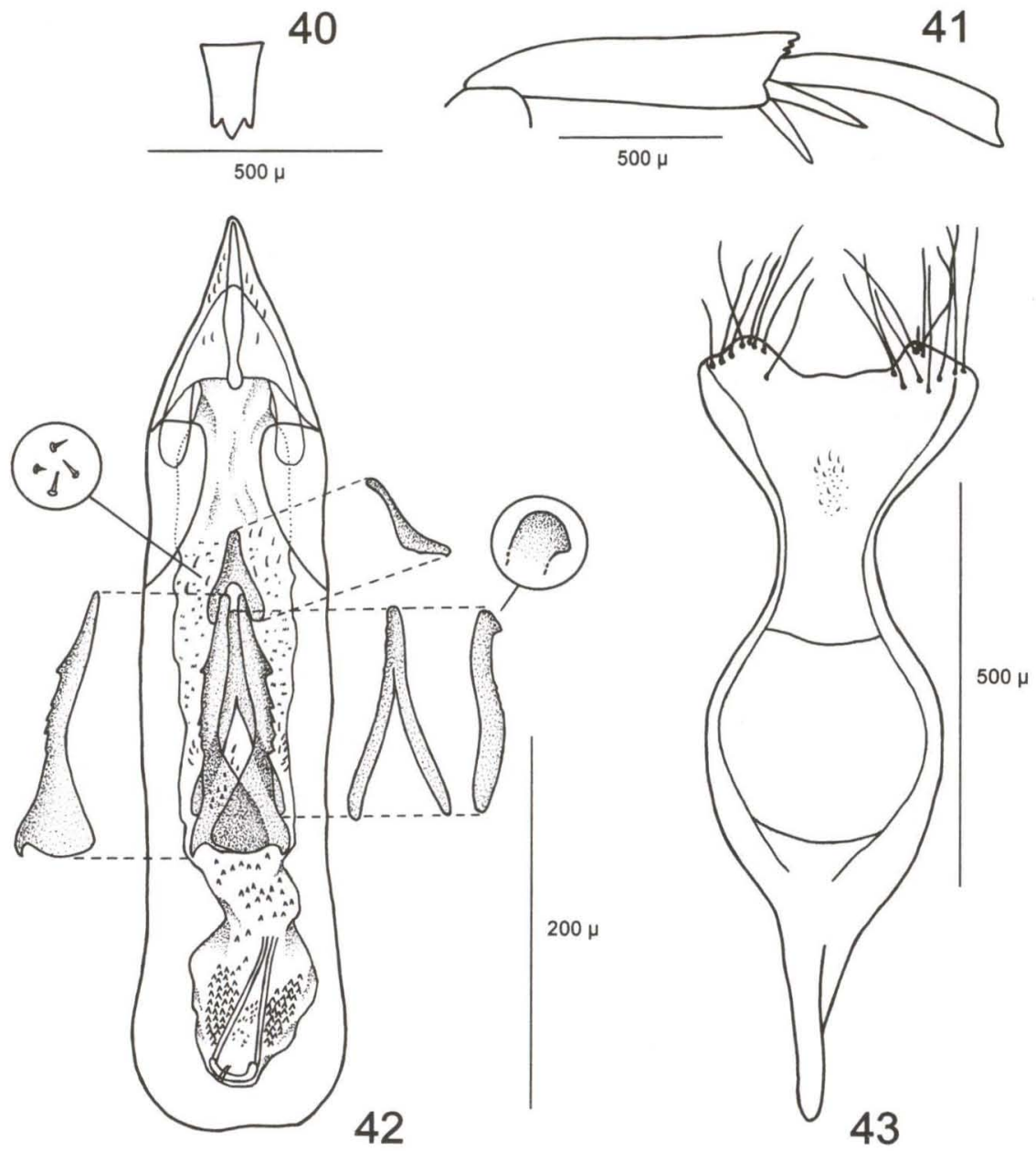

Figs 40-43. Amblycerus pusillus sp.n.. (40) Escutelo; (41) tíbia e primeiro artículo tarsal da perna posterior; (42-43) terminália do macho: (42) lobo médio; (43) tégmen.

pontos grossos no meio. Escutelo cerca de 2,4 vezes mais longo que largo, com ápice tridenteado; o dente mediano levemente mais longo que os laterais (Fig. 40). Fêmur posterior cerca de 2,6 vezes tão longo quanto largo. Tíbia posterior (Fig. 41) com esporão lateral quase tão longo quanto o comprimento do mediano; o primeiro artículo tarsal posterior o dobro do lateral e cerca de 2,7 vezes o esporão mediano; face ventral plana com linha de pontos e cerdas grossas conspícuas nas margens. Quinto esterno abdominal visível subtruncado no macho e na fêmea.

Terminália do macho (Figs 42-43). Lobo médio (Fig. 42) com comprimento 5,6 vezes a sua maior largura na região basal; valva ventral com margens laterais levemente côncavas. Região basal do saco interno com um esclerito posterior subtriangular, levemente sinuoso e com hastes apicais. Região mediana do saco interno com um par de escleritos laminares levemente arqueados, serreados na 
margem submediana; os dentes aproximados; um esclerito impar em forma de forquilha 0,8 vezes tão longo quanto os laminares e com base denteada. Tégmen (Fig. 43) não emarginado entre os alargados lobos laterais.

Discussão taxonômica. Dentre as espécies brasileiras, A. pusillus sp.n. parece mais relacionada à $A$. cerdanicola Kingsolver, 1970, espécie incluída no grupo "scutellaris" estabelecido por ROMERo et al. (1996). Difere da mesma principalmente pelo formato do esclerito da região basal do saco interno, da terminália do macho (Fig. 42) que é subquadrado, com base arredondada e sem hastes apicais em $A$. cerdanicola.

Holótipo macho, BRAsIL, Paraná: Fênix, Reserva Est.-ITCF; 03.XI.1986, Lev. Ent. Profaupar, Lâmpada, (DZUP). Quatro parátipos do Brasil: um com os mesmos dados do holótipo exceto com data de 31.III.1987 (DZUP); dois [Mato Grosso], Chapada [dos Guimarães], XI, [H. H. Smithleg.], Acc. No.2966, 1 (CMNH), 1 (DZUP) e um mesmos dados exceto XII, (CMNH).

Etimologia. O nome da espécie refere-se ao tamanho diminuto. Amblycerus pusillus sp.n. é uma das menores espécies brasileiras de Amblycerus.

AGRADECIMENTOS. Ao Dr. John M. Kingsolver pelo acesso às notas sobre os tipos de Amblycerus, ao Pe. Jesus S. Moure pelas sugestões na elaboração dos nomes de espécies novas, a Dra. Danúncia Urban pela revisão do manuscrito e aos responsáveis pelo desenvolvimento do Projeto de Levantamento da Fauna Entomológica do Estado do Paraná - PROFAUPAR, em especial ao coordenador, Prof. Dr. Renato Contin Marinoni.

\section{REFERÊNCIAS BIBLIOGRÁFICAS}

Kingsolver, J.M. 1970. A synopsis of the subfamily Amblycerinae Bridwell in the West Indies, with descriptions of new species (Coleoptera: Bruchidae). Trans. Amer. Entomol. Soc. 96: 469-497.

- 1975. Amblycerus acapulcensis, a new species of seed beetle from Mexico (Coleoptera: Bruchidae). Jour. Wash. Acad. Sci. 65 (1): 33-35.

1980. Eighteen new species of Bruchidae, principally from Costa Rica, with host records and distributional notes (Insecta: Coleoptera). Proc. Biol. Soc. Wash. 93 (1): 229-283.

- 1991. A new species of Amblycerus (Coleoptera: Bruchidae) from Central and South America, with notes on its biology. Proc. ent. Soc. Wash. 93 (2): 433-436.

RibeIRo-Costa, C.S. 1998 [1997]. Descrições de oito novas espécies de Amblycerus Thunberg (Coleoptera, Bruchidae). Revta bras. Zool. 14 (3): 629-648.

- 1999a. Description of two new species of Amblycerus Thunberg (Coleoptera: Bruchidae) with a probable stridulatory mechanism. Proc. ent. Soc. Wash. 101 (2): 337-346.

-1999b. Descrições de duas espécies novas de Amblycerus Thunberg (Coleoptera, Bruchidae).

Revta bras. Zool. 16 (Supl.1): 233-238.

- 1999c. Sete novas espécies de bruquídeos do gênero Amblycerus Thunberg (Coleoptera, Bruchidae). Revta bras.Zool. 16 (3): 789-806.

Ribeiro-Costa, C.S. \& J.M. Kingsolver. 1993a. Two new species of Amblycerus Thunberg, 1815 (Coleoptera: Bruchidae) and a lectotype designation. Insecta Mundi 6 (3): 183-187.

.1993b. Amblycerus teutoniensis (Coleoptera: Bruchidae), a new species of seed beetle. Ent.

News $104(4): 160-164$.

Romero, J.; C.D. Johnson \& J.M. Kingsol.ver. 1996. Revision of the genus Amblycerus of the United States and Mexico (Coleoptera: Bruchidae:Amblycerinae). U.S. Dept. Agric., Technical Bull. (1845): 1-166.

Recebido em 08.VII.1999; aceito em 20.III.2000 